\title{
Role of stem cell factor in the regulation of ICC proliferation and detrusor contraction in rats with an underactive bladder
}

\author{
JIANLI FENG, JIN GAO, SHAN ZHOU, YUANFENG LIU, YU ZHONG, YONG SHU, \\ MING SEN MENG, JIAQIANG YAN, DANNING SUN, QIANG FANG and DAODONG SUN \\ Department of Urology, Chongqing 324 Hospital of PLA, Chongqing 400020, P.R. China
}

Received June 7, 2016; Accepted April 12, 2017

DOI: $10.3892 / \mathrm{mmr} .2017 .6749$

\begin{abstract}
Stem cell factor (SCF) is critical in regulating the proliferation, differentiation and function of the interstitial cells of Cajal (ICCs), which are closely associated with smooth muscle dysfunction. The present study aimed to examine the effect of SCF on ICC proliferation and detrusor contraction in rats with an underactive bladder. Sprague-Dawley rats were divided into four groups comprising control, control+SCF, detrusor underactivity (DU), and DU+SCF groups. The ICC count was determined using immunofluorescence; serum levels of SCF were determined using an enzyme-linked immunosorbent assay; mRNA and protein levels of c-kit and SCF in tissues were assessed using reverse transcription-quantitative polymerase chain reaction and western blot analyses, respectively. Detrusor contractility was determined using muscle strips, based on the contraction amplitude and frequency determined in each specimen. Significantly fewer ICCs were observed in the DU group, in addition to decreased expression levels of SCF and c-kit, compared with the control group. In addition, the detrusor contraction frequency and amplitude were markedly reduced. However, the administration of SCF significantly increased the number of ICCs, and the levels of SCF and c-kit in animals with DU, and resulted in markedly amplified detrusor contraction frequency and amplitude. Similarly, the number of ICCs and levels of SCF and c-kit were higher in the control+SCF group, compared with the control group. Overall, these findings suggested that exogenous SCF improved the organ dysfunction caused by reduced ICC number, providing a novel approach for organ repair.
\end{abstract}

Correspondence to: Dr Daodong Sun, Department of Urology, Chongqing 324 Hospital of PLA, 29 Jianxin East Road, Jiangbei, Chongqing 400020, P.R. China

E-mail: windflycome@163.com

Key words: bladder dysfunction, detrusor underactivity, stem cell factor, interstitial cells of Cajal, bladder outlet obstruction, underactive bladder

\section{Introduction}

Detrusor underactivity (DU) is a common bladder dysfunction in clinical practice. It is characterized by reduced bladder detrusor contractility or decreased contractility duration, leading to delayed or incomplete bladder voiding (1). Typical clinical manifestations of DU include urinary hesitancy and dysuria. In addition, those with DU can experience increased nocturia, increased urinary frequency and urgency, and urinary incontinence. Therefore, DU can seriously affect patient quality of life. The pathogenesis of DU involves neurogenic, muscle-genic, age-related and iatrogenic factors. However, the pathophysiologic mechanisms of DU remains to be fully elucidated (2).

The interstitial cells of Cajal (ICCs) are a specific type of interstitial cell in the gastrointestinal tract; the activation of c-kit receptors on the surface of ICCs is intimately associated with their proliferation, differentiation and function (3). The activation of c-kit relies on its ligand, stem cell factor (SCF) (3). SCF is of neural and smooth muscle origin $(4,5)$, and is involved in the regulation of cell proliferation, differentiation and migration (6). Therefore, SCF is important in regulating the proliferation, differentiation and function of ICCs $(7,8)$.

ICCs are present in multiple smooth muscle organs and are closely associated with organ dysfunction (9-11). It has been suggested that ICCs have a pacemaker-like function in the gastrointestinal tract (12). Studies have shown that a change in SCF leads to altered ICC numbers, which contributes to gastrointestinal dysmotility $(9,10,13)$. In the urinary tract, ICCs serving as a pacemaker are found in the tissues of the renal pelvis and ureter (14-16). ICCs are also present in the bladder $(17,18)$. The association between ICCs and bladder dysfunction has been examined previously. An overactive bladder, a common bladder dysfunction, is associated with an increased number of ICCs $(19,20)$. However, there have been few investigations evaluating the association between an underactive bladder and ICCs, and the pathophysiological mechanisms of an underactive bladder remain to be elucidated. The present study hypothesized that DU may be associated with the SCF-mediated alterations in ICCs. Therefore, the present study aimed to examine changes in ICCs in the context of DU, and evaluate the effect of SCF on ICCs in addition to the changes in detrusor contractility. 


\section{Materials and methods}

Animals. A total of 90 female Sprague-Dawley (SD) rats (weight, 190-220 g; age, 3 months) were used in the present study. Rats were housed at $\sim 24^{\circ} \mathrm{C}$ with a $12 \mathrm{~h}$ light/dark cycle (on $7 \mathrm{AM} /$ off $7 \mathrm{PM}$ ) and 35-40\% humidity. Rats were given free access to food and water throughout the study. All experiments were performed at the Central Laboratory of the Third Military Medical University Affiliated Southwest Hospital (Chongqing, China). All animal experiments were approved by the animal ethics committee of the Third Military Medical University. The bladder outlet obstruction (BOO) rat model was established using the bladder outlet obstruction method (21). Briefly, anesthesia was achieved by intraperitoneal injection of 3\% pentobarbital sodium (30 mg $/ \mathrm{kg}$; Sigma-Aldrich; Merck Millipore, Darmstadt, Germany). Subsequently, a median abdominal incision was performed to expose the bladder and proximal urinary tract. A $1.1 \mathrm{~mm}$ diameter polyethylene pipe was inserted into the bladder transurethrally, with 1-0 thread used for urethral ligation and the degree of ligation defined by appropriate movement with the urethral catheter. The incision was sutured following catheter removal. In the sham group, the urethra was exposed but not ligated. After 8 weeks, bladder filling pressure measurements were performed using a micro perfusion pump (AVI 270; 3M Company, Saint Paul, MN, USA) and a urodynamic instrument (Nidoc 970A+; Wearnes UEST New Tech Co., Ltd., Chengdu, China), and rats with DU were observed. Animal condition was monitored by measuring animal body temperature at 8.00 a.m., 4.00 p.m., and 12.00 p.m. daily using a biological remote sensing system (TA10TA-F40 Data Sciences International, St. Paul, MN, USA). In addition, mental health and overall activity were assessed twice every day; animal weights were measured weekly. Following surgery, the rats were housed in separate cages; at 3 and 6 days post-surgery, they were housed with 3 and 5 per cage, respectively. The current protocols required that seriously ill or moribund rats (no activity and/or eating) be administered with injectable anesthetic euthanasia.

The animals were divided into control $(\mathrm{n}=18)$, control+SCF $(\mathrm{n}=18), \mathrm{DU}(\mathrm{n}=18)$ and DU+SCF $(\mathrm{n}=18)$ groups. SCF was dissolved in PBS and administered at $0.2 \mu \mathrm{g} / \mathrm{kg} / \mathrm{d}$ by intraperitoneal injection. The control and DU group animals were intraperitoneally injected with equal volumes of PBS. The rats were sacrificed 2 weeks later by intraperitoneal injection of $3 \%$ pentobarbital sodium $(100 \mathrm{mg} / \mathrm{kg})$, and bladder specimens were collected for the determination of ICC number, expression levels of c-kit and SCF in the detrusor, and alterations of detrusor contractility using an in vitro muscle strip experiment.

No animals became ill or died in the sham-operated group. When suspected with illness, the rats were housed in single cages, which were cleaned daily. In the BOO group, one rat died on day 3 , two rats died on day 42 , and one rat died on day 48 post-surgery. In addition, one animal in the DU+SCF group died 5 days post-injection. The possible causes of death are described below. In the $\mathrm{BOO}$ group, the rat which died on day 3 post-surgery had surgical trauma-induced stress. Postoperative infection (increased body temperature) was the cause of death of one of the rats on day 42 , whereas the other died of unknown causes. Postoperative kidney disease with retention, which can lead to hydronephrosis or renal failure, led to the death of the animal on day 48. In the DU+SCF group, the rat died on day 5 as a result of bladder stones.

Assessment of ICC numbers in the detrusor using immunohistochemistry. The rats were sacrificed, and the bladder and proximal urinary tract were exposed. Proximal urinary obstruction was removed, and a polyethylene catheter was inserted. The bilateral ureters were ligated using 1-0 silk, following which the bladder was inflated by injection of 4\% paraformaldehyde through the urethral catheter, which was subsequently removed prior to rapid ligation of the proximal urethra. The proximal urethra and bilateral ureter were incised, followed by bladder removal and preservation in $4 \%$ paraformaldehyde at $21^{\circ} \mathrm{C}$ for $30 \mathrm{~min}$. The samples were then transferred to $0.1 \mathrm{M} \mathrm{PBS}$ and incubated at $21^{\circ} \mathrm{C}$ overnight. The bladder was longitudinally incised the following day, and lateral walls measuring $4 \times 4 \mathrm{~mm}$ were harvested. The mucosal and serosal layers were carefully dissected and separated under a microscope (XTS-4A; Zhenjiang Zhongtian Optical Instrument Co., Ltd., Zhenjiang, China). The specimens were blocked in $1 \%$ bovine serum albumin (Sigma-Aldrich; Merck Millipore) at room temperature for $1 \mathrm{~h}$ and subsequently incubated with anti-c-kit primary antibody (1:100; cat.no. sc-1494; Santa Cruz Biotechnology, Inc., Dallas, TX, USA) for $24 \mathrm{~h}$ at $4^{\circ} \mathrm{C}$. Finally, the samples were incubated with secondary antibody (1:100; cat.no. sc-2356; Santa Cruz Biotechnology, Inc.) at room temperature for $1 \mathrm{~h}$ and then rinsed in $0.01 \mathrm{M}$ PBS for $2 \mathrm{~h}$ prior to examination under a confocal microscope (LSCM, Leica TCS-NT, Germany) for determination of the expression of c-kit in the cells. The rat small intestines were used as positive controls. Five high power fields from each sample were randomly selected, and samples were collected from different groups in a blinded manner by different examiners. Cell counts of the c-kit positive cells were recorded.

Expression of SCF in plasma determined using an enzymelinked immunosorbent assay (ELISA). Blood samples ( $2 \mathrm{ml})$ were collected from the rats prior to sacrifice. The concentrations of SCF in the plasma was determined using an ELISA kit (Abcam, Cambridge, UK) according to manufacturer's protocol.

Protein levels of c-kit and SCF in detrusor using western blot analysis. The detrusor ( $25 \mathrm{mg}$ ) was harvested and homogenized. The homogenate was added to lysate buffer for $30 \mathrm{~min}$ at $4^{\circ} \mathrm{C}$, and subjected to centrifugation at $12,000 \mathrm{~g}$ for $8 \mathrm{~min}$ at $4^{\circ} \mathrm{C}$. The supernatants were collected, and protein concentrations determined using a NanoDrop ND-1000 (NanoDrop; Thermo Fisher Scientific, Inc., Wilmington, DE, USA). The total protein samples $(50 \mu \mathrm{g})$ were resolved by $10 \%$ sodium dodecyl sulfate polyacrylamide gel electrophoresis and electrotransferred onto nitrocellulose membranes. Following blocking with 5\% skimmed milk for $2 \mathrm{~h}$, the membranes were incubated with primary antibodies raised against SCF (1:200; cat.no sc-9132; Santa Cruz Biotechnology, Inc.), c-kit (1:100; cat.no. sc-1494; Santa Cruz Biotechnology, Inc.) and glyceraldehyde 3 phosphate dehydrogenase (GAPDH; 1:500; cat.no. A00191; GenScript, Piscataway, NJ, USA). The membranes were then washed with PBST three times prior to incubation with appropriate HRP-conjugated secondary 
antibodies (1:500; cat.nos. sc-2357 and sc-2354; Santa Cruz Biotechnology, Inc.) for $1 \mathrm{~h}$ at $37^{\circ} \mathrm{C}$; detection was performed with Millipore Immobilon Western Chemiluminescent HRP substrate (EMD Millipore, Billerica, MD USA). Band intensities were determined using image process software (Bio-Rad Gel Doc 2000; Bio-Rad Laboratories, Inc., Hercules, CA, USA).

Determination of gene expression levels of c-kit and SCF in detrusor samples using reverse transcription-quantitative polymerase chain reaction $(R T-q P C R)$ analysis. The bladder tissue specimens ( $30 \mathrm{mg}$ ) were homogenized and lysed using Tripure lysate (Roche Diagnostics, Basel, Switzerland) for RNA preparation, according to the manufacturer's protocol. Total RNA was extracted using TRIzol reagent (Thermo Fisher Scientific, Inc., Waltham, MA, USA) according to the manufacturer's protocol. RNA quantity and integrity were assessed using spectrophotometry and gel electrophoresis, respectively. RNA $(1 \mu \mathrm{g})$ was used as a template for cDNA synthesis using a GeneAmp RNA PCR kit (Applied Biosystems; Thermo Fisher Scientific, Inc.) according to the manufacturer's instructions. qPCR analysis was performed using Power SYBR ${ }^{\circledR}$ Green PCR Master Mix (Applied Biosystems; Thermo Fisher Scientific, Inc.) on an Applied Biosystems 7900HT Fast Real-Time qPCR system. qPCR was performed in a $20 \mu 1$ reaction volume, containing $2 \mu \mathrm{l}$ cDNA, $0.6 \mu \mathrm{l}$ primers, $10 \mu \mathrm{l} 2 \mathrm{X}$ SYBR green and $7.4 \mu \mathrm{l}$ RNA free $\mathrm{H}_{2} \mathrm{O}$. Thermocycling conditions involved an initial denaturation step of $96^{\circ} \mathrm{C}$ for $5 \mathrm{~min}$, followed by 40 cycles of a three-step program of $96^{\circ} \mathrm{C}$ for $30 \mathrm{~s}, 57^{\circ} \mathrm{C}$ for $30 \mathrm{~s}$ and $72^{\circ} \mathrm{C}$ for $30 \mathrm{~s}$, followed by a final extension step at $72^{\circ} \mathrm{C}$ for $10 \mathrm{~min}$. qPCR was conducted three times for each gene of interest. The primers used were as follows: c-kit, forward 5'-TGC CGGTCGATTCCAAGTTT-3' and reverse 5'-GCCGACGGA ATTGACCCTC-3' (target fragment 269 bp); SCF, forward 5'-CCTGCAATATGA AGCCCCAAGAC-3' and reverse 5'-GGTGCCCTCCTGCTACTTTTAC-3' (target fragment 166 bp); GAPDH, forward 5'-CCGCCCCTTCCGCTGATG-3' and reverse 5'-CCGCCTGCTTCACCACCTTCTT-3' (target fragment $432 \mathrm{bp}$ ). The $2^{-\Delta \Delta \mathrm{Cq}}$ method was used to analyze the PCR data (22), expressed as the fold change relative to the expression of GAPDH.

Detection of detrusor contractility using in vitro assays of muscle strips. The rats underwent anesthesia, and the bladder and proximal urethra were exposed as described above. The muscle strips $(7 \times 2 \mathrm{~mm})$ were prepared and stored in $5 \mathrm{ml}$ Krebs's solution ( $\mathrm{pH} 7.4)$ at $37^{\circ} \mathrm{C}$ in an atmosphere containing $5 \% \mathrm{CO}_{2}$. The ends of the longitudinal muscle strips were placed on metal hooks with a tension sensor (Chengdu Instrument Company, Chengdu, China) connected to a biological laboratory data system (RM6240; Chengdu Instrument Company). The muscle strips were placed in an organ bath for $30 \mathrm{~min}$ prior to recording contractility, with an initial tension of $0.3 \mathrm{~g}$. The amplitude of the contraction wave was defined as the wave height, between the base and peak. The frequency of contraction was defined as the mean contraction frequency within 5 min.

Statistical analysis. All experiments were performed three times in total. Values are presented as the mean \pm standard deviation. Differences among or between groups were assessed using one-way analysis of variance or Student's t-test, using SPSS 19.0 software (IBM SPSS, Armonk, NY, USA). $\mathrm{P}<0.05$ was considered to indicate a statistically significant difference.

\section{Results}

SCF improves bladder micturition contraction in rats with $D U$. The bladder pressure was measured in vivo by the micturition contraction wave during gradual bladder filling, the results of which are shown in Fig. 1A. Compared with the control group, the amplitude and frequency of bladder micturition contraction were significantly decreased in the DU group, as shown in Fig. $1 \mathrm{~B}$ and $\mathrm{C}$, respectively. The control+SCF group showed significantly higher amplitude and frequency of bladder micturition contraction, compared with the control group. Similarly, the amplitude and frequency of bladder micturition contraction were higher in the DU+SCF group, compared with the DU group.

Exogenous administration of SCF results in increased plasma levels of SCF. The levels of SCF in plasma, as assessed using ELISA, are shown in Fig. 2. The plasma levels of SCF in the control+SCF group animals $(529.6 \pm 28.3 \mathrm{ng} / \mathrm{l})$ were higher, compared with the values obtained in the control group animals $(396.1 \pm 20.2 \mathrm{ng} / \mathrm{l} ; \mathrm{P}<0.05)$. Compared with the control group, the plasma levels of SCF in rats of the DU group $(208.5 \pm 13.9 \mathrm{ng} / \mathrm{l})$ were significantly decreased. However, following administration of exogenous (DU+SCF group), the plasma levels of SCF were significantly increased to $384.5 \pm 18.7 \mathrm{ng} / \mathrm{l}(\mathrm{P}<0.05)$, suggesting that exogenous $\mathrm{SCF}$ markedly improved the levels of SCF in animals with DU.

SCF increases ICC counts in rats with DU. The ICC counts in rat detrusor specimens were determined using immunofluorescence and shown in Fig. 3A-H. Classical spindle-like ICCs were widely distributed in the submucosal and muscular layers. Compared with the control rats, significantly fewer ICCs were found in the submucosal and intermuscle bundles layers of the DU group, (Fig. 3I; P<0.05). Upon administration of exogenous SCF (DU+SCF group), ICC counts in the rat detrusor specimens were significantly increased (Fig. 3I), suggesting that SCF markedly improved ICC count in the underactive detrusor. This was also reflected by increased values in the control+SCF group, compared with the control group (Fig. 3I).

SCF administration results in induced expression of SCF and c-kit, at the gene and protein levels. The gene expression levels of SCF and c-kit in rat detrusor samples were detected using RT-qPCR analysis. Compared with the control group, the mRNA levels of SCF and c-kit in the DU group were significantly decreased $(\mathrm{P}<0.05)$. However, administration of exogenous SCF (DU+SCF group) significantly increased the mRNA levels of SCF and c-kit (Fig. 4), indicating that $\mathrm{SCF}$ induced the gene expression of SCF and c-kit in DU. In agreement, the control+SCF group showed significantly higher mRNA levels of SCF and c-kit, compared with the control group (Fig. 4). 
A

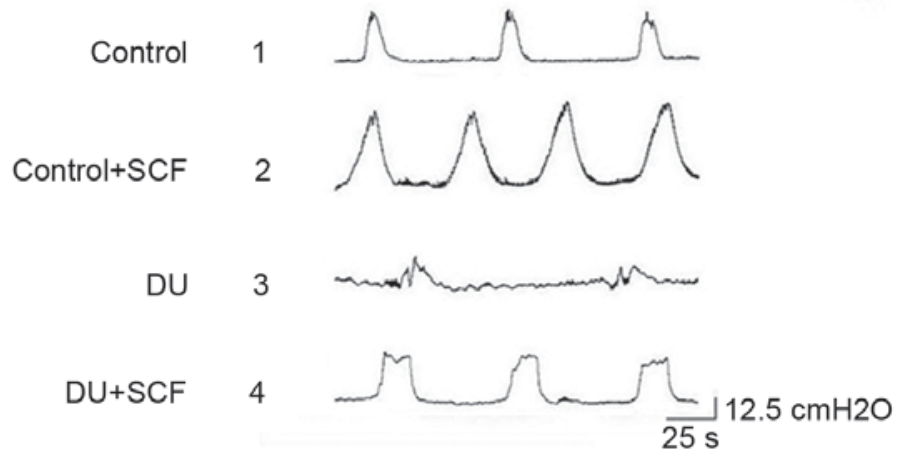

B

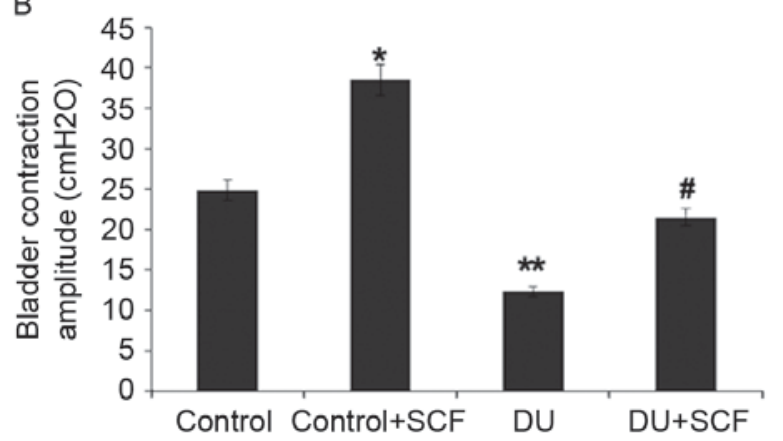

C

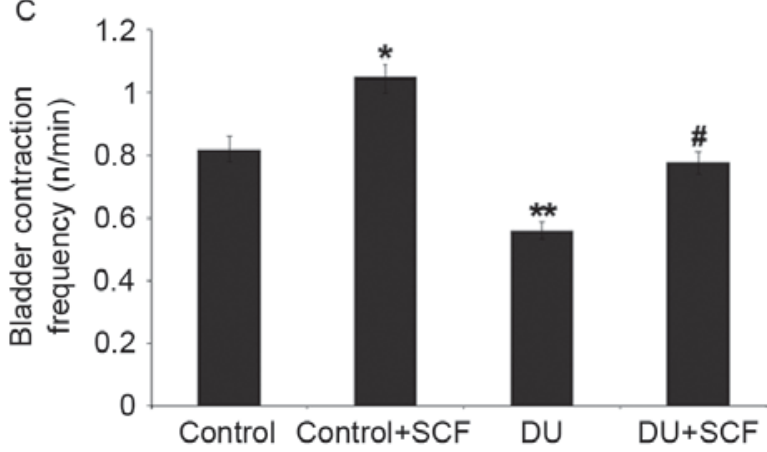

Figure 1. Bladder micturition contraction. (A) Results obtained from the control, control+SCF, DU, and DU+SCF groups. (B) Amplitude of bladder micturition and $(\mathrm{C})$ frequency of bladder micturition contraction among the treatment groups $(\mathrm{n}=8)$. ${ }^{*} \mathrm{P}<0.05$ and ${ }^{* *} \mathrm{P}<0.01$, compared with the control group; ${ }^{\#} \mathrm{P}<0.05$, compared with the DU group. DU, detrusor underactivity; SCF, stem cell factor.

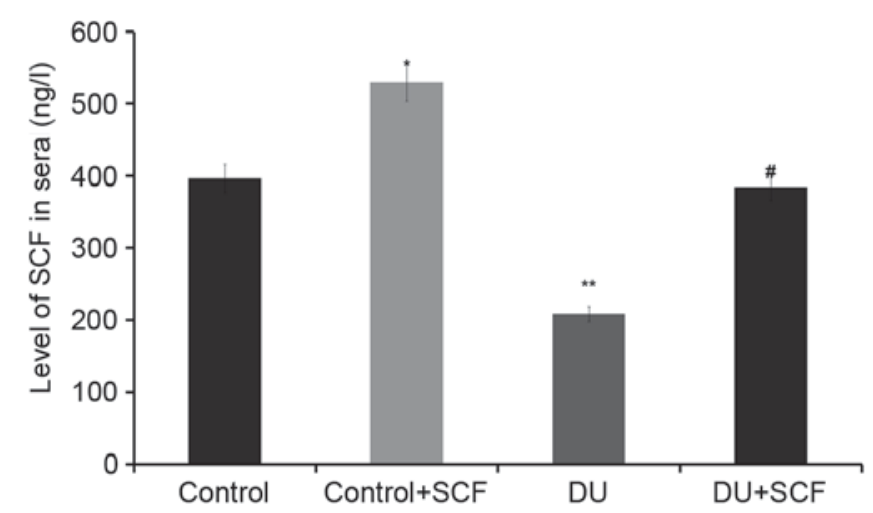

Figure 2. SCF levels in rat plasma samples of different treatment groups. Plasma levels of SCF were determined using an enzyme-linked immunosorbent assay $(\mathrm{n}=8) .{ }^{*} \mathrm{P}<0.05$ and ${ }^{* *} \mathrm{P}<0.01$, compared with the control group; ${ }^{\#} \mathrm{P}<0.05$, compared with the DU group. DU, detrusor underactivity; SCF, stem cell factor.

As shown in Fig. 5, the protein levels of SCF and c-kit in the DU group were also significantly reduced, compared with those in the control group $(\mathrm{P}<0.05)$, an effect alleviated by the exogenous administration of SCF, as observed in the DU+SCF group. Similarly, the protein levels of SCF and c-kit were significantly increased in the control+SCF group, compared with the control group. These findings indicated that exogenous SCF increased the protein expression levels of SCF and c-kit in DU.

SCF restores detrusor contractility in rats with $D U$. The results of the in vitro muscle contraction experiment are shown in Fig. 6. As shown in Fig. 6A, and quantified in Fig. 6B and C, the detrusor contraction amplitude and frequency were markedly decreased in the DU group, compared with those in the control group $(\mathrm{P}<0.05)$. Of note, SCF administration significantly increased the amplitude and frequency of muscle contraction $(\mathrm{P}<0.05$ for $\mathrm{DU}+\mathrm{SCF}$ group, vs. DU group and control+SCF, vs. control group), suggesting that exogenous SCF restored contractility in DU.

\section{Discussion}

The present study revealed that partial obstruction of bladder outlet contributed to a significant change of bladder function. Obstruction for 8 weeks led to significant decreases in contraction amplitude and frequency, suggesting successful establishment of the DU model.

Several studies investigating bladder dysfunction have focused on the overactive bladder $(19,20)$, whereas few have investigated the underactive bladder. The pathophysiological mechanisms of underactive detrusor remain to be elucidated and have attracted increasing attention.

ICCs are interstitial cells distributed in smooth muscles in several organs; they are closely associated with multiple organ dysfunction (8-11). Following 6 weeks of obstruction, the bladder detrusor shows compensatory hypertrophy with markedly increased function and a significant increase in ICC cell counts (23). These findings correspond with previous studies $(24,25)$ demonstrating that ICCs are closely associated with detrusor function.

In the present study, a BOO rat model was established, and animals with DU were assessed. As described above, 

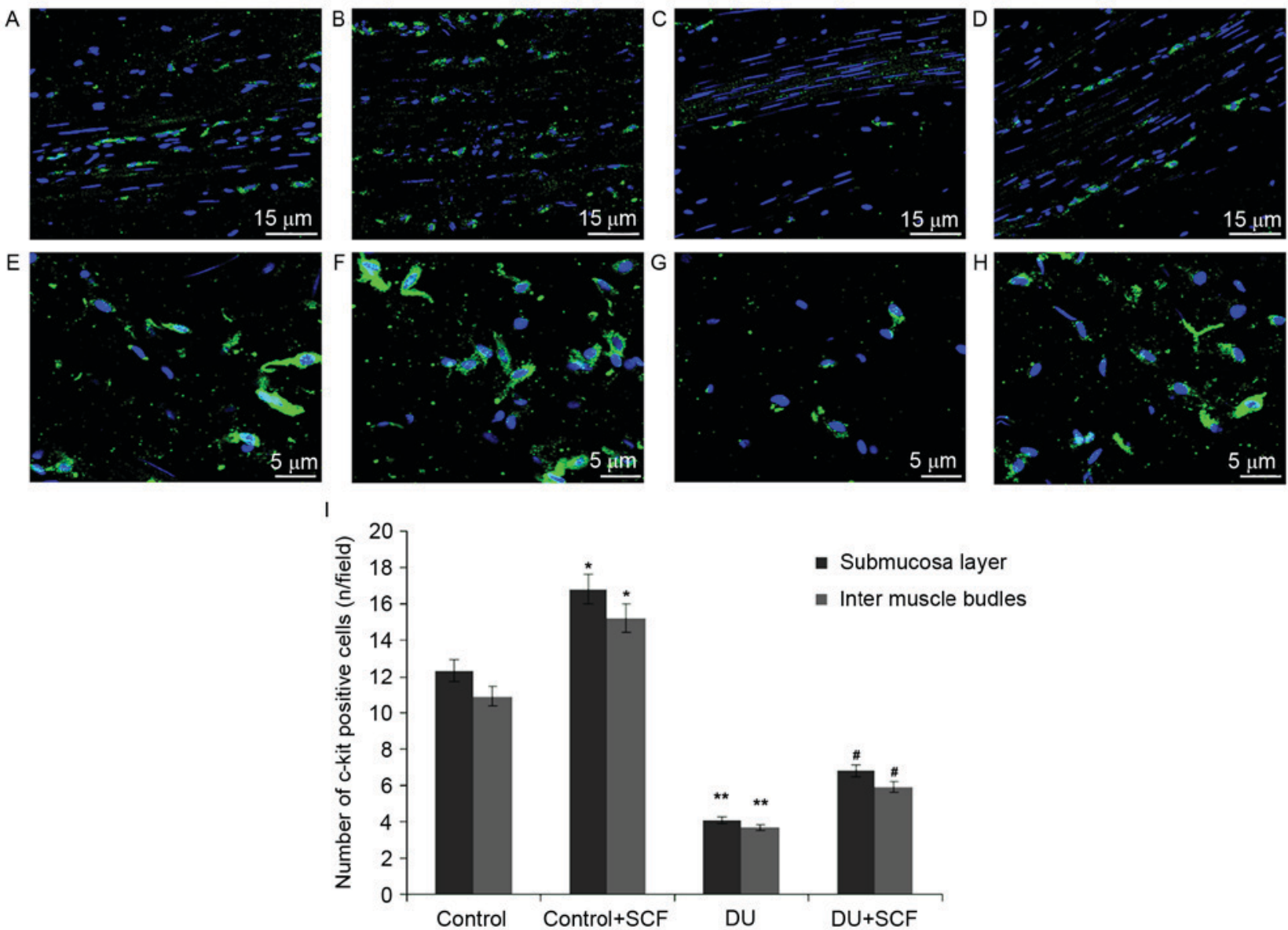

Figure 3. ICC counts in rat detrusor samples. Nuclei are stained blue and ICCs are stained green. Intermuscle bundles in the (A) control group, (B) control+SCF group, (C) DU group and (D) DU+SCF group. Submucosa layers in the (E) control group, (F) control+SCF group, (G) DU group and (H) DU+SCF group. (I) Quantitation of $\mathrm{A}-\mathrm{H}(\mathrm{n}=8){ }^{*} \mathrm{P}<0.05$ and ${ }^{* *} \mathrm{P}<0.01$, compared with the control group; ${ }^{*} \mathrm{P}<0.05$, compared with the DU group. DU, detrusor underactivity; SCF, stem cell factor.

ICC counts in the detrusor from rats with underactive bladders were significantly decreased, compared with those in the control rats; however, the underlying mechanisms remain to be elucidated. Previous studies have shown that decreased ICC counts are caused by ICC phenotype redifferentiation instead of death (7), which may be closely associated with SCF. A study by Lin et al (13) found a significant decrease in ICC counts in the colon of diabetic mice, which was associated with decreased levels of SCF. Theresults of the present study showed that the levels of SCF were decreased in underactive detrusor tissues and plasma samples, and the levels of c-kit in the detrusor tissues were significantly reduced, resulting in markedly reduced ICC counts and dysfunctional contraction. These findings corroborate with other reports demonstrating that SCF is involved in regulating the proliferation and differentiation of ICC, and is thus involved in regulating organ motility. Nakahara et al (26) showed that ICCs have a dose-dependent and time-limited proliferation response to SCF. In addition, Tong et al (27) revealed that exogenous SCF improved ICC number and function via the SCF/c-kit pathway, with a high SCF concentration having increased potency. In agreement, the results of the present study demonstrated that exogenous SCF upregulated the expression of c-kit in damaged detrusor tissues, contributing to increased ICC number and restoring contractility of the underactive detrusor.

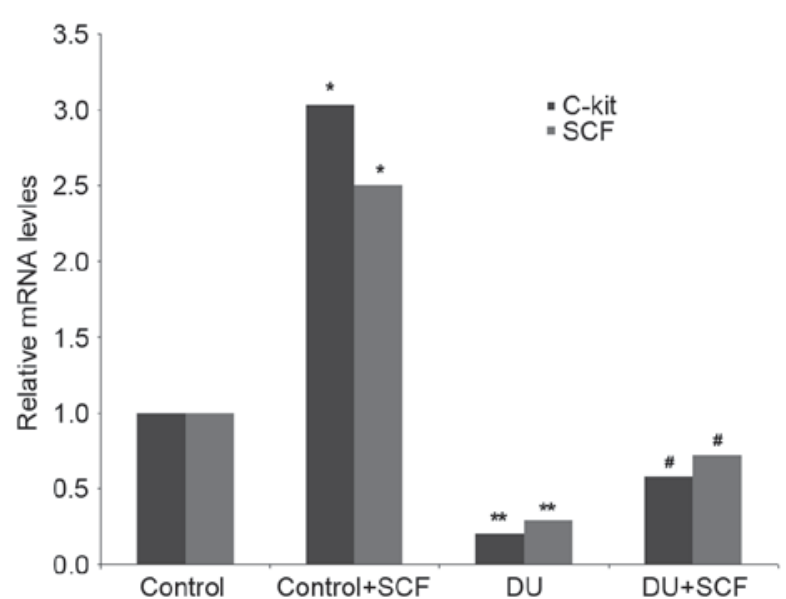

Figure 4. mRNA levels of SCF and c-kit in rat detrusor specimens. Gene expression levels were determined using reverse transcription-quantitative polymerase chain reaction analysis, with the housekeeping gene GAPDH as an internal control $(n=8) .{ }^{*} \mathrm{P}<0.05$ and ${ }^{* *} \mathrm{P}<0.05$, compared with the control group; ${ }^{\text {"}} \mathrm{P}<0.05$, compared with the DU group. DU, detrusor underactivity; SCF, stem cell factor.

The results of the present study indicated that exogenous $\mathrm{SCF}$ and c-kit were involved in regulating ICC count and function. Exogenous SCF improved the organ dysfunction caused 
A

SCF

Control Control+SCF DU DU+SCF

GAPDH

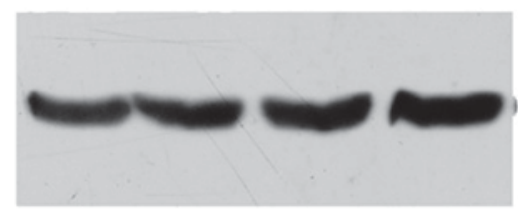

B

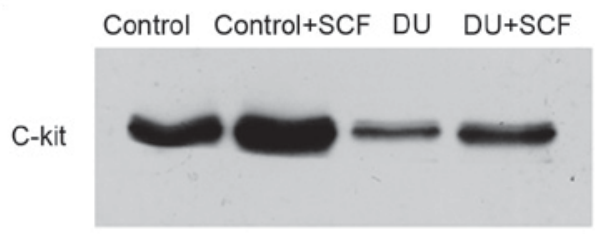

GAPDH

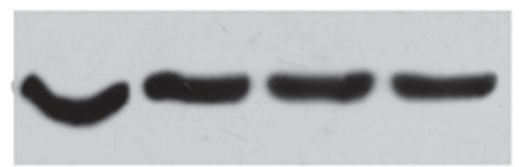

C

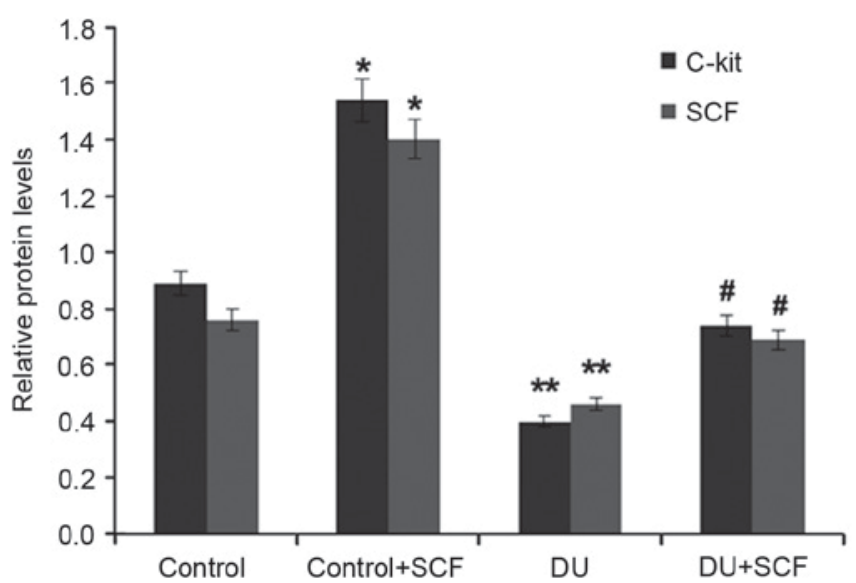

Figure 5. Protein levels of SCF and c-kit. Protein levels were assessed using western blot analysis. Western blot membranes showing expression of (A) SCF and (B) c-kit in rat detrusor samples. (C) Relative protein expression levels of SCF and c-kit, quantified from the blots ( $\mathrm{n}=8$ ). ${ }^{*} \mathrm{P}<0.05$ and ${ }^{* *} \mathrm{P}<0.01$, compared with the control group; ${ }^{*} \mathrm{P}<0.05$, compared with the DU group. DU, detrusor underactivity, $\mathrm{SCF}$, stem cell factor.

A

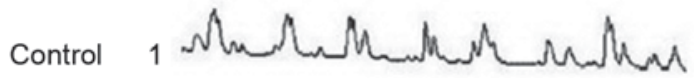

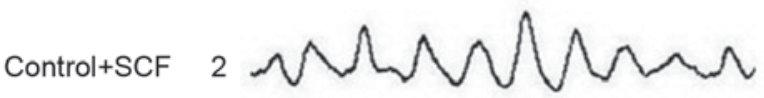

DU 3

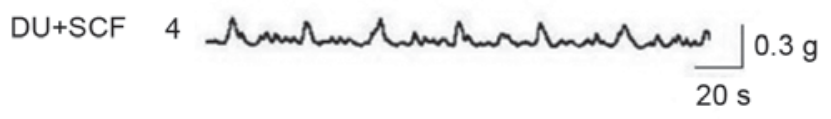

B

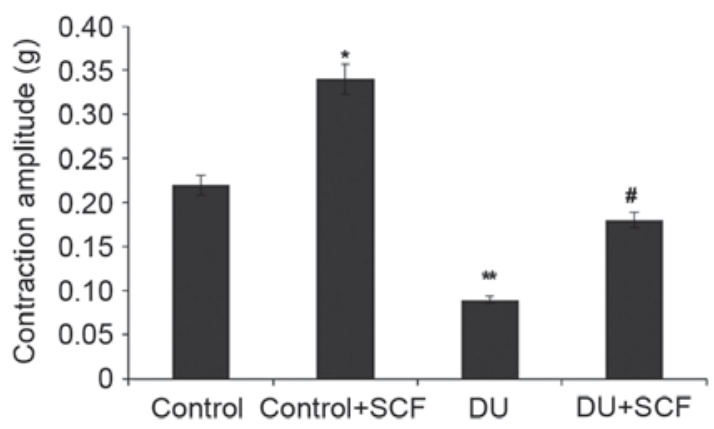

C

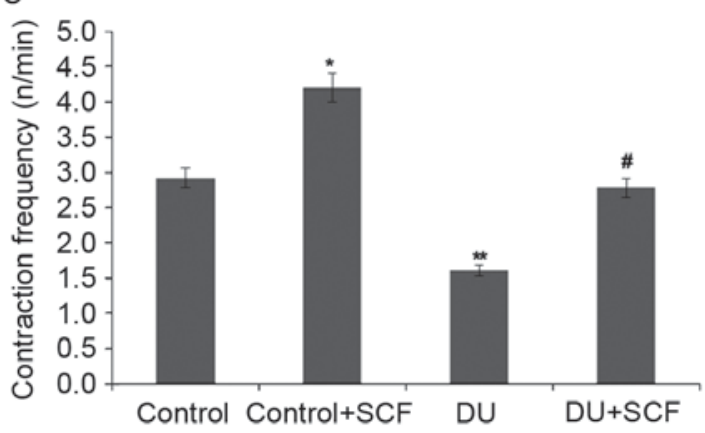

Figure 6. Assessment of detrusor contractility using a muscle strip experiment. (A) Contractility curve of rat detrusor in the control, control+SCF, DU, and DU+SCF groups. (B) Amplitude of muscle strip contraction. (C) Frequency of muscle strip contraction ( $\mathrm{n}=8) .{ }^{*} \mathrm{P}<0.05$ and ${ }^{* * *} \mathrm{P}<0.01$, compared with the control group; ${ }^{~} \mathrm{P}<0.05$, compared with the DU group. DU, detrusor underactivity; SCF, stem cell factor. 
by a reduction in ICC number, providing a novel approach for repairing the dysfunction of organs, including DU.

\section{Acknowledgements}

This study was supported by a grant from the Chongqing Natural Science Foundation (grant no. cstc2012jjA1566).

\section{References}

1. Abrams P, Cardozo L, Fall M, Griffiths D, Rosier P, Ulmsten U, van Kerrebroeck P, Victor A and Wein A; Standardisation Sub-committee of the International Continence Society: The standardisation of terminology of lower urinary tract function: Report from the Standardisation Sub-committee of the International Continence Society. Neurourol Urodyn 21: 167-178, 2002.

2. Taylor JA III and Kuchel GA: Detrusor underactivity: Clinical features and pathogenesis of an underdiagnosed geriatric condition. J Am Geriatr Soc 54: 1920-1932, 2006.

3. Lorincz A, Redelman D, Horvath VJ, Bardsley MR, Chen H and Ordög T: Progenitors of interstitial cells of cajal in the postnatal murine stomach. Gastroenterology 134: 1083-1093, 2008.

4. Horvath VJ, Vittal H, Lörincz A, Chen H, Almeida-Porada G, Redelman D and Ordög T: Reduced stem cell factor links smooth myopathy and loss of interstitial cells of cajal in murine diabetic gastroparesis. Gastroenterology 130: 759-770, 2006.

5. Nishimura M, Koda K, Oda K, Seike K, Shimizu K and Miyazaki M: Mesenteric transection decreases expression of interstitial cells of Cajal in an experimental model. Br J Surg 94 483-490, 2007.

6. Galli SJ, Tsai M and Wershil BK: The c-kit receptor, stem cell factor, and mast cells. What each is teaching us about the others. Am J Pathol 142: 965-974, 1993.

7. Torihashi S, Nishi K, Tokutomi Y, Nishi T, Ward S and Sanders KM: Blockade of kit signaling induces transdifferentiation of interstitial cells of cajal to a smooth muscle phenotype. Gastroenterology 117: 140-148, 1999.

8. Wu JJ, Rothman TP and Gershon MD: Development of the interstitial cell of Cajal: Origin, kit dependence and neuronal and nonneuronal sources of kit ligand. J Neurosci Res 59: 384-401, 2000.

9. Forrest A, Huizinga JD, Wang XY, Liu LW and Parsons M: Increase in stretch-induced rhythmic motor activity in the diabetic rat colon is associated with loss of ICC of the submuscular plexus. Am J Physiol Gastrointest Liver Physiol 294: G315-G326, 2008.

10. Yamamoto T, Watabe K, Nakahara M, Ogiyama H, Kiyohara T, Tsutsui S, Tamura S, Shinomura Y and Hayashi N: Disturbed gastrointestinal motility and decreased interstitial cells of Cajal in diabetic db/db mice. J Gastroenterol Hepatol 23: 660-667, 2008.

11. Kubota M, Kanda E, Ida K, Sakakihara Y and Hayashi M: Severe gastrointestinal dysmotility in a patient with congenital myopathy: Causal relationship to decrease of interstitial cells of Cajal. Brain Dev 27: 447-450, 2005.
12. Thomsen L, Robinson TL, Lee JC, Farraway LA, Hughes MJ, Andrews DW and Huizinga JD: Interstitial cells of Cajal generate a rhythmic pacemaker current. Nat Med 4: 848-851, 1998

13. Lin L, Xu LM, Zhang W, Ge YB, Tang YR, Zhang HJ, Li XL and Chen JD: Roles of stem cell factor on the depletion of interstitial cells of Cajal in the colon of diabetic mice. Am J Physiol Gastrointest Liver Physiol 298: G241-G247, 2010.

14. Lang RJ, Tonta MA, Zoltkowski BZ, Meeker WF, Wendt I and Parkington HC: Pyeloureteric peristalsis: Role of atypical smooth muscle cells and interstitial cells of Cajal-like cells as pacemakers. J Physiol 576: 695-705, 2006.

15. Pezzone MA, Watkins SC, Alber SM, King WE, de Groat WC, Chancellor MB and Fraser MO: Identification of c-kit-positive cells in the mouse ureter: The interstitial cells of Cajal of the urinary tract. Am J Physiol Renal Physiol 284: F925-F929, 2003.

16. Yang X, Zhang $\mathrm{Y}$ and $\mathrm{Hu} \mathrm{J}$ : The expression of Cajal cells at the obstruction site of congenital pelviureteric junction obstruction and quantitative image analysis. J Pediatr Surg 44: 2339-2342, 2009.

17. McCloskey KD and Gurney AM: Kit positive cells in the guinea pig bladder. J Urol 168: 832-836, 2002.

18. Davidson RA and McCloskey KD: Morphology and localization of interstitial cells in the guinea pig bladder: Structural relationships with smooth muscle and neurons. J Urol 173: 1385-1390, 2005.

19. Kim SO, Song SH, Ahn KY and Kwon DD: Distribution of interstitial cells of cajal in menopausal rat urinary bladder showing detrusor overactivity. Int Neurourol J 14: 48-53, 2010.

20. Kubota Y, Kojima Y, Shibata Y, Imura M, Sasaki S and Kohri K: Role of KIT-positive interstitial cells of Cajal in the urinary bladder and possible therapeutic target for overactive bladder. Adv Urol 2011: 816342, 2011

21. Sutherland RS, Baskin LS, Kogan BA and Cunha G: Neuroanatomical changes in the rat bladder after bladder outlet obstruction. Br J Urol 82: 895-901, 1998.

22. Livak KJ and Schmittgen TD: Analysis of relative gene expression data using real-time quantitative PCR and the 2(-Delta Delta C(T)) method. Methods 25: 402-408, 2001.

23. Wang Y, Fang Q, Lu Y, Song B, Li W and Li L: Effects of mechanical stretch on interstitial cells of Cajal in guinea pig bladder. J Surg Res 164: e213-e219, 2010

24. Kim SO, Oh BS, Chang IY, Song SH, Ahn K, Hwang EC, Oh KJ, Kwon D and Park K: Distribution of interstitial cells of Cajal and expression of nitric oxide synthase after experimental bladder outlet obstruction in a rat model of bladder overactivity. Neurourol Urodyn 30: 1639-1645, 2011.

25. Kubota Y, Hashitani H, Shirasawa N, Kojima Y, Sasaki S, Mabuchi Y, Soji T, Suzuki H and Kohri K: Altered distribution of interstitial cells in the guinea pig bladder following bladder outlet obstruction. Neurourol Urodyn 27: 330-340, 2008.

26. Nakahara M, Isozaki K, Vanderwinden JM, Shinomura Y, Kitamura Y, Hirota S and Matsuzawa Y: Dose-dependent and time-limited proliferation of cultured murine interstitial cells of Cajal in response to stem cell factor. Life Sci 70: 2367-2376, 2002.

27. Tong W, Jia H, Zhang L, Li C, Ridolfi TJ and Liu B: Exogenous stem cell factor improves interstitial cells of Cajal restoration after blockade of c-kit signaling pathway. Scand J Gastroenterol 45: 844-851, 2010. 